\title{
An Enhanced Learning Environment for Institutions: Implementing i-Converge's Pedagogical Model
}

\author{
Oludele Awodele, Sunday Idowu, Vincent Jonah Joshua, \\ Omotola Anjorin, Adebunmi Adedire, and Victoria Akpore \\ Babcock University, Ilishan-Remo, Ogun State, Nigeria
}

\author{
delealways@yahoo.com; saidowu06@hotmail.com; \\ jvjoshua@hotmail.com; anjorin jinr@hotmail.com; \\ bunmie me@yahoo.com; vicakpore@yahoo.co.uk
}

\begin{abstract}
E-learning systems have evolved from basic instructional tools to sophisticated systems capable of providing robust virtual learning environment, where students can benefit from long distance courses with learning experience comparable to physical classroom courses.

However, while e-learning systems are experiencing a proliferated development and adoption by schools in both developed and undeveloped economy, in most cases, there still exist a gap between the e-learning application and other non-academic services and community within the institution.

This paper explains the development, implementation and use of an extended e-learning system named $i$-Converge that uses a social networking approach to enhance activities in a university. The system is built on a model that attempts to integrate several entities within the academic institution with a view to providing a holistic, and comprehensive learning system where information exchange is simplified and enhanced between all stakeholders in the institution. The system although implemented for use in a university will be further extended and implemented for use in any institution.
\end{abstract}

Keywords: Social Networking, Integration, eLearning, Learning, Collaboration, Web 2.0, Universities

\section{Introduction}

We have in our recent work (Awodele, Idowu, Anjorin, Adedire, \& Apkore, 2009) discussed the use of social tools, particularly in e-learning systems. In that work we suggested and discussed a

Material published as part of this publication, either on-line or in print, is copyrighted by the Informing Science Institute. Permission to make digital or paper copy of part or all of these works for personal or classroom use is granted without fee provided that the copies are not made or distributed for profit or commercial advantage AND that copies 1) bear this notice in full and 2) give the full citation on the first page. It is permissible to abstract these works so long as credit is given. To copy in all other cases or to republish or to post on a server or to redistribute to lists requires specific permission and payment of a fee. Contact Publisher@InformingScience.org to request redistribution permission. model that provides the basis for the development of an enhancement system. We also analysed the trend of e-learning systems in developing countries, and also discussed the social approach to learning. While e-learning is widely used in learning institutions, its use has been profound in the business environment. 
Presently, we focus on adapting our model and implementing it for a university environment. According to Awodele et al. (2009), we suggested that to effectively impact the learning pattern of higher institutions, especially in Nigeria and other developing countries, the application of ICT should not be focused only on administrative issues like online registration, payment etc but the primary objective of the institution, which is learning should be made more effective and efficient by adopting relevant ICT tools. Furthermore, we emphasized that to further maximize the potential of e-learning systems in higher institutions, it is important not to adopt e-learning systems that concentrates only on the students and their lecturers (the academic community), but also the nonacademic or administrative community within the institution should be considered and integrated into the system. We therefore advocated for a system where several learning barriers can be eliminated by opening the learning environment to include non-academic staffs (who can contribute immensely to the entire learning experience), and integrating the key departments/sections (academic and administrative) into the learning system with a view to improving the information flow. This would provide students with relevant information alongside large academic resources and also aid the workers in performing their activities effectively.

Like recent e-learning solutions built on Web 2.0 tools, tagged e-learning 2.0. The system discussed in this paper adopts the use of social tools to develop an e-learning system that breaks the teacher-student-classroom pedagogy and implements a social constructivist approach. This pedagogy is particularly well afforded by the use of discussion forums, blogs, wiki and on-line collaborative activities. It is a collaborative approach that opens educational content creation to a wider group including the students themselves. Since Web 2.0 involves a high degree of user involvement and social networking, it has influenced e-learning systems in terms of pedagogy and delivery. Anderson (2007) describes six big ideas behind Web 2.0 as follows:

- Individual production and User Generated Content

- Harness the power of the crowd

- Data on an epic scale

- Architecture of participation

- Network Effects

- Openness

According to Anderson (2007), Brown \& Adler (2008), and O'Reilly (2005), Web 2.0 could facilitate a change of paradigm in learning; from a top-down system focused in teachers and established knowledge, to a networked approach where teachers should change their roles to become coaches and facilitators of the learning process. This therefore suggests that the strength of emerging e-learning solutions lies in the use of Web 2.0 tools; also the necessity to enhance academic (learning) activities in institutions by adopting e-learning has been stated by Aviram, Aviram, Ronen, Somekh, Winer, and Sarid (2008). According to these authors, it is obvious that the traditional pedagogical approach is no longer meeting the needs to prepare young learners to function effectively and satisfactorily in today's challenging labour market.

Research has shown that most newly proposed/developed learning and administrative systems for higher institutions are built on a new (different) pedagogical model, which argues a personalized and social approach while leveraging and incorporating Web 2.0 tools. An e-learning system like $i$-Converge that adopts social tools and attempts to integrate non-academic/administrative system would be best institutionalized into the private university system to give them a comparative edge over other tertiary institutions. It has been discovered that students would find the learning process more interesting if dynamism is a part of the process instead of the monotonous classroom teaching method. The system being proposed is such that gives the learner the autonomy to learn 
at his or her own pace, make learning a lifelong experience and introduces collaboration, where students do have the opportunity of learning not only from their instructors but also from a wide educative resource globally.

The rest of this paper briefly discusses our model, the need in learning institutions and shows the implementation of our developed e-learning solution $i$-Converge.

\section{Private University: History and Success Story}

Not until 1999, the university system in Nigeria was dominated by federal and state universities. The educational experience in the country hitherto 1999 wasn't too encouraging. Several menace existed in these long live universities, some of which includes rampant strikes, cultism which often resulted to loss of lives, assaults and poor infrastructural development.

Since the year 1999 when private universities began to spring up with pioneer institutions like Babcock University, Ilishan-Remo, Madonna University, Okija and Igbinedion University, Okada. The educational system of Nigeria has experienced a change as the competition for standard, quality and efficiency erupted all over the country. From 1999 till date, several other private universities like Covenant University, Ota, Pan-African University, Lagos, Bowen University Iwo and several others have been established and accredited by the National Universities Commission (NUC).

According to Obasi (2007) the successes of private universities in Nigeria which is a challenge to public universities includes stable academic calendar, absence of frequent strikes by staff and demonstrations by students, relatively secure and peaceful learning environment characterized by near absence of secret cults, clean dormitory environment among many others. He further reported the following achievements:

- Increased female enrolment.

- Achievement of optimum balance between academic-non-academic staff ratio.

- Effective check on, and reduction of the menace of secret cult activities.

- Restoration of the badly eroded dignity and welfare of student life.

- Maintenance of stable academic calendar.

Despite the fact that most private universities are not-for-profit and do not receive funds from the government. They have exhibited efficient leadership in terms of management of funds and infrastructural development. Presently private universities are in the fore-front of ICT adoption in the country, Babcock University for example if one of the few universities in the country that runs a total online registration system with operation starting from payment to course, room allocation and time tabling to result checking. The ICT base of the university is relatively strong with a campus wide networking covering the entire school.

The adoption of ICT in private universities is more feasible considering the fact that they are relatively new and can still adjust their structures, policy and system(s) to suit new technology. Similarly, the fact that the student size is relatively fewer as compared to federal and state universities, and also most students in private universities are equipped with laptops makes it easy and convenient for them to adopt a system like $i$-Converge to further simplify and enhance the learning activities. 


\section{Enhanced Learning Environment}

We simply define a learning environment by the surrounding in or at which an individual engages in any conscious activity that results to the acquisition or sharing of knowledge and/or information.

This definition basically expands the activities that take place in classrooms. In most private universities in Nigeria at the moment, learning still occur primarily in lecture rooms which implies that there is little or no out of class learning activity or collaboration whatsoever. The reason for this eminent in causes like classroom constraint, student size to lecturer ratio etc, it is therefore to crucial to create a tool that can assist lecturers deliver their courses easily, efficiently and in an accessible manner regardless of time, classroom constraint and number of students. Also, it is important to simplify the learning process on the part of students by bringing the content to them wherever they are, making them active rather than passive participants and also emphasizing convenience, privacy, collaboration and other important issues.

An entire university surrounding can be turned into a holistic learning environment by enabling every member of the institution to participate in the learning process, this way an invaluable social capital can be harnessed for the institution. It is also important to know that collaboration can exist within and outside the institution, and the external effect of collaboration is actually what yields the network and group effects.

By an enhanced learning environment we mean an integrated, simplified, accessible, customizable and collaborative learning environment. Figure 1 depicts the model upon which $i$-Converge is built.

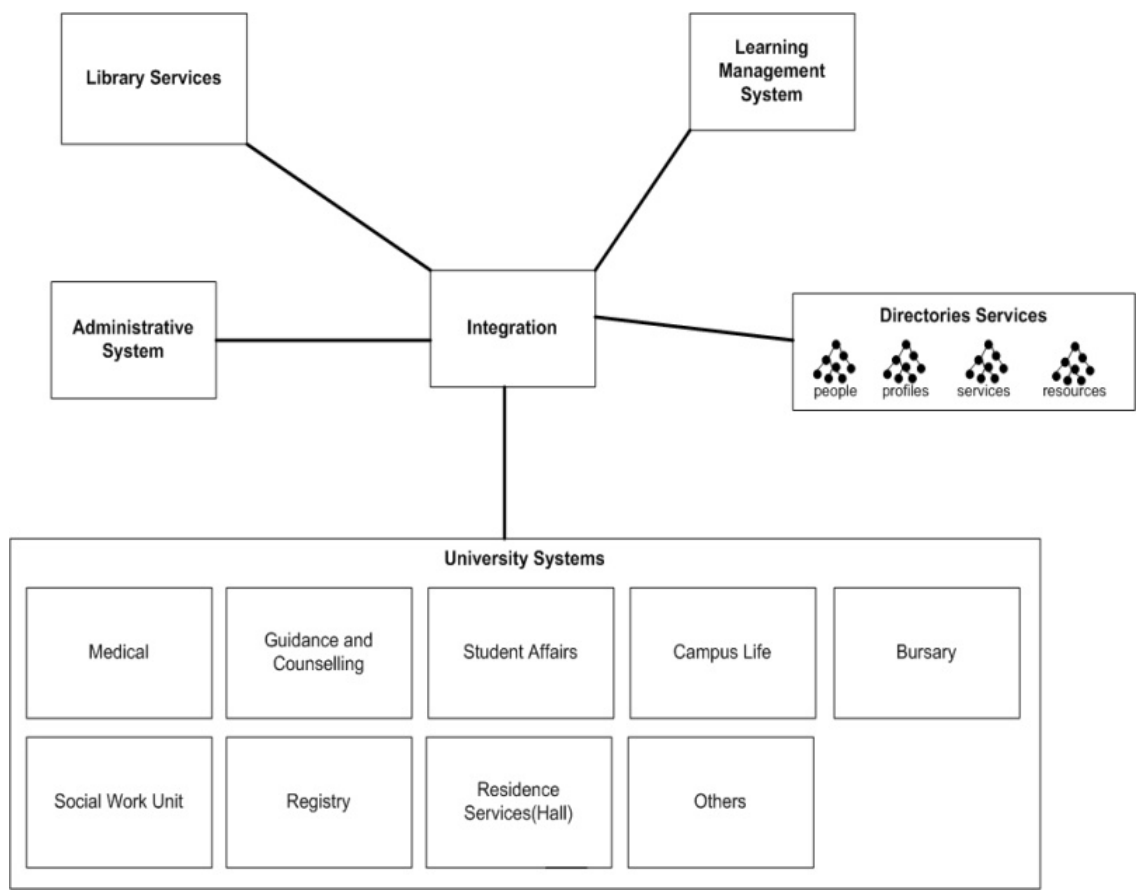

Figure 1: Extended e-learning system

The system is made up of the following components:

- Library Services

- Administrative System

- Directory Services 
- Learning Management System (LMS)

- University Services

The components in the model are not necessarily standard; rather they depict the primary subsystems of what can make up an extended learning environment (Awodele et al., 2009). The model emphasizes two basic ideas:

- Integration of other non-academic activities/services into the learning system.

- Contribution/participation of non-academic personnel's in the learning process.

In this paper, we will briefly discuss the Learning Management System component. Other components were explained in our previous work (Awodele et al., 2009).

\section{Learning Management System (LMS)}

At the core of this integrated system is the LMS, which is a vital part of the entire system. However, instead of having the e-learning system entirely built as LMS, the LMS part of the model manages the learning aspect (notes creation, grade book, discussion forums, virtual classrooms etc) and forms part of the entire system.

\section{i-Converge's Design}

$i$-Converge is a Rich Internet Application (RIA) designed with several tools which includes Adobe Flex, Adobe Coldfusion, Adobe Flash Media Server 3 and Microsoft SQL Server 2005. It is designed to run on an intranet and/or the internet.

The system is designed with flexibility in mind; therefore consideration for expansion was paramount in the design. Other factors considered in the design include security, portability, usability and reusability. These non-functional requirements are components of the ISO 9126 Quality Model, developed by International Organization for Standardization (ISO). This model is a useful tool to evaluate the quality of e-learning systems, particularly for teachers and educational administrators (Chua \& Dyson, 2004). We tried to ensure that $i$-Converge conforms to the ISO 9126 standard.

\section{Implementation}

This section uses screenshots to show the features and use of $i$-Converge. Figure 2 shows the login page which is displayed when a user accesses the application by pointing a browser to the appropriate address. Users are required to specify a username and password which can be preassigned, with a default password that they are expected to change after login. It is also possible to let users sign up for a username and password, which will be sent to an email address provided.

The login page is shown in Figure 2: 


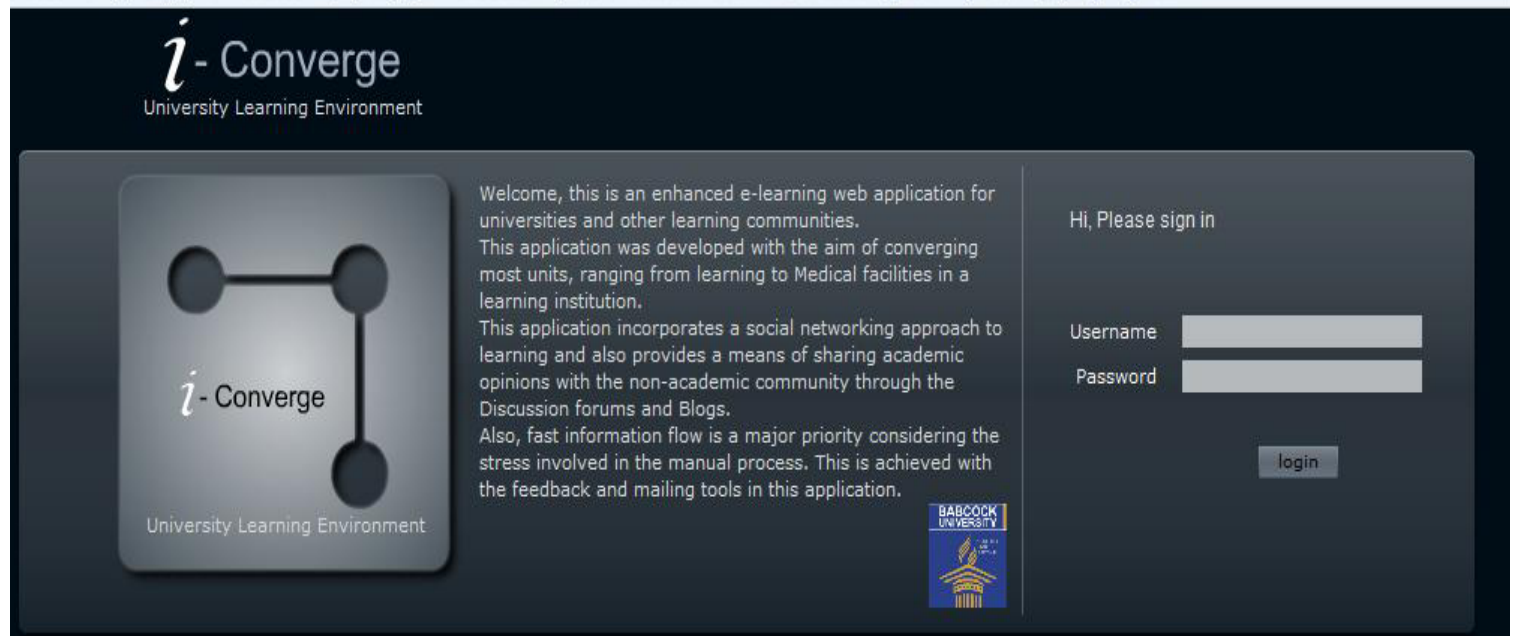

Figure 2: Login Page.

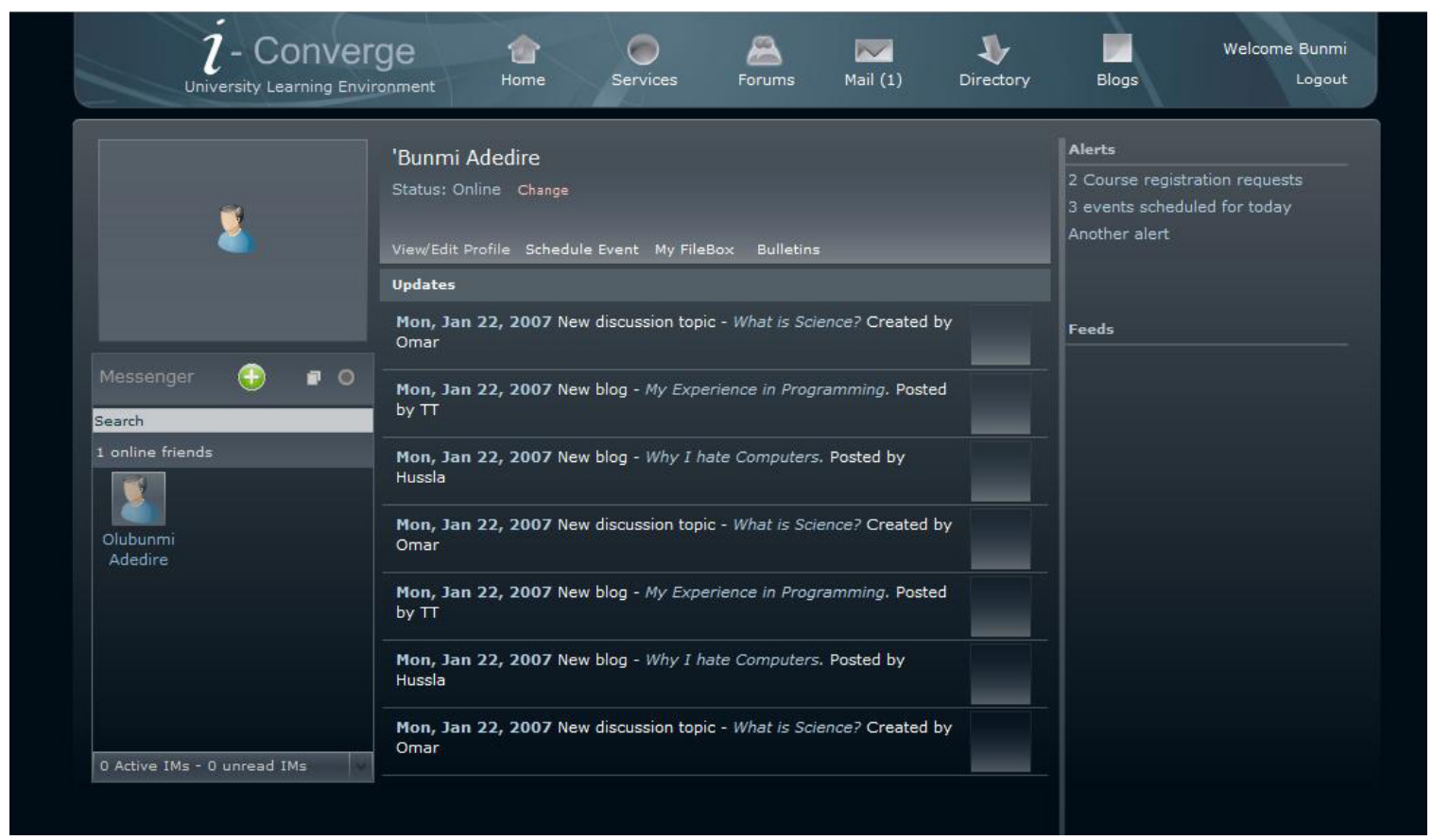

Figure 3: Welcome Page for Users.

Figure 3 shows the welcome page for users. The application is designed to provide a unique customizable environment for users. The environment of each user is different, based on their preferences and category, e.g., students, lecturers, administrative staffs and guests. The central focus is to have a personal learning environment (PLE) for users. At the top is the navigation bar, where the user can select places to go.

At the right side is the alert and feeds bar that notifies the user of recent events. At the left side are the user image and the instant messaging window. The updates bar at the middle provides real time information update for the user. 


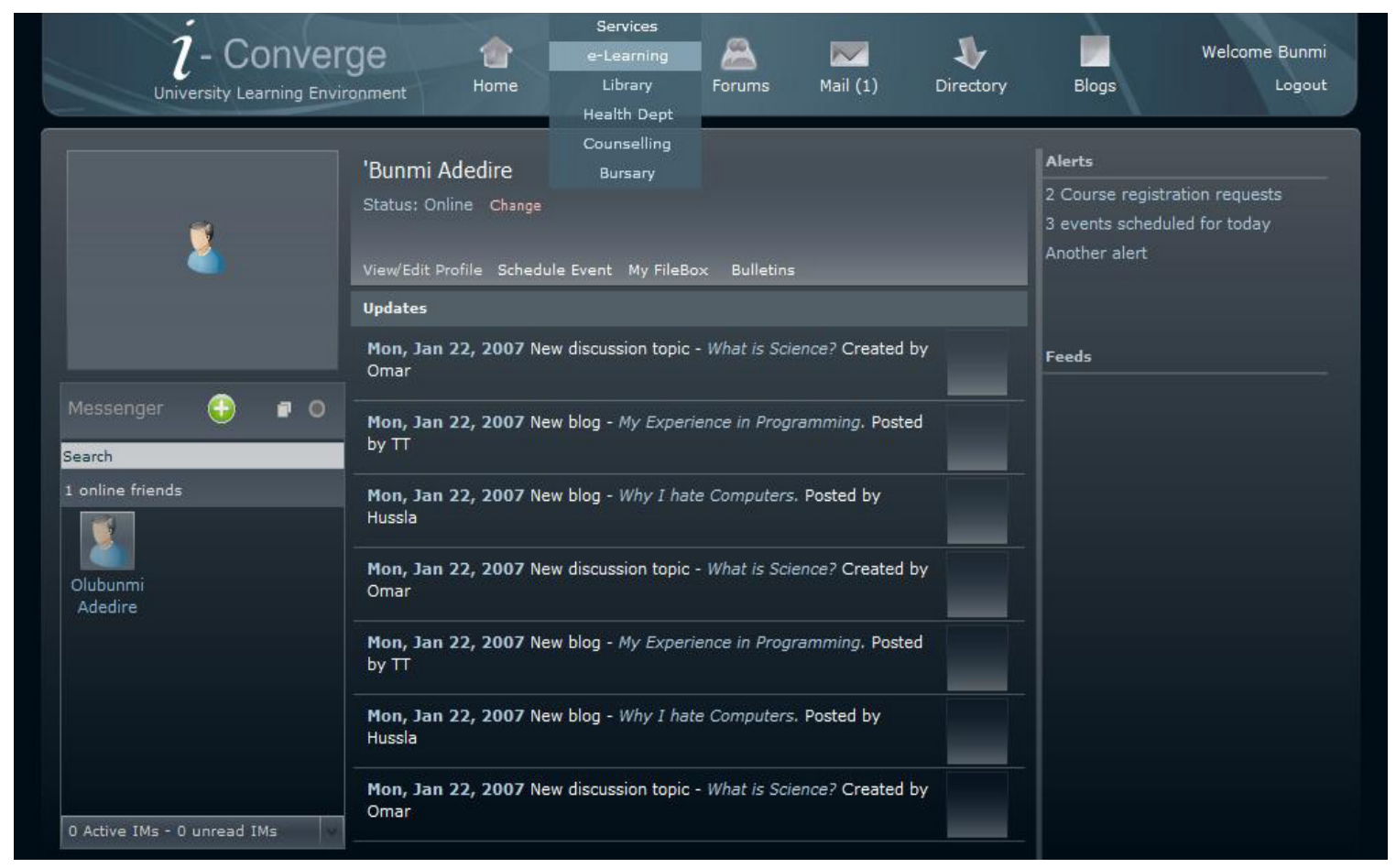

Figure 4: Menu Navigation

Figure 4 shows how a user navigates for the different services available. These services avails the user the opportunity to interact with a component of the model which could the LMS or other University Systems. The University Systems services could be built and integrated with the learning environment or interfaced to communicate with external systems.

When a user clicks on the Services link, the options e-learning, Library, Health Dept etc are presented. The user can then select the appropriate service he/she wants to use. Selecting the elearning options, presents the user the LMS part of the system. 


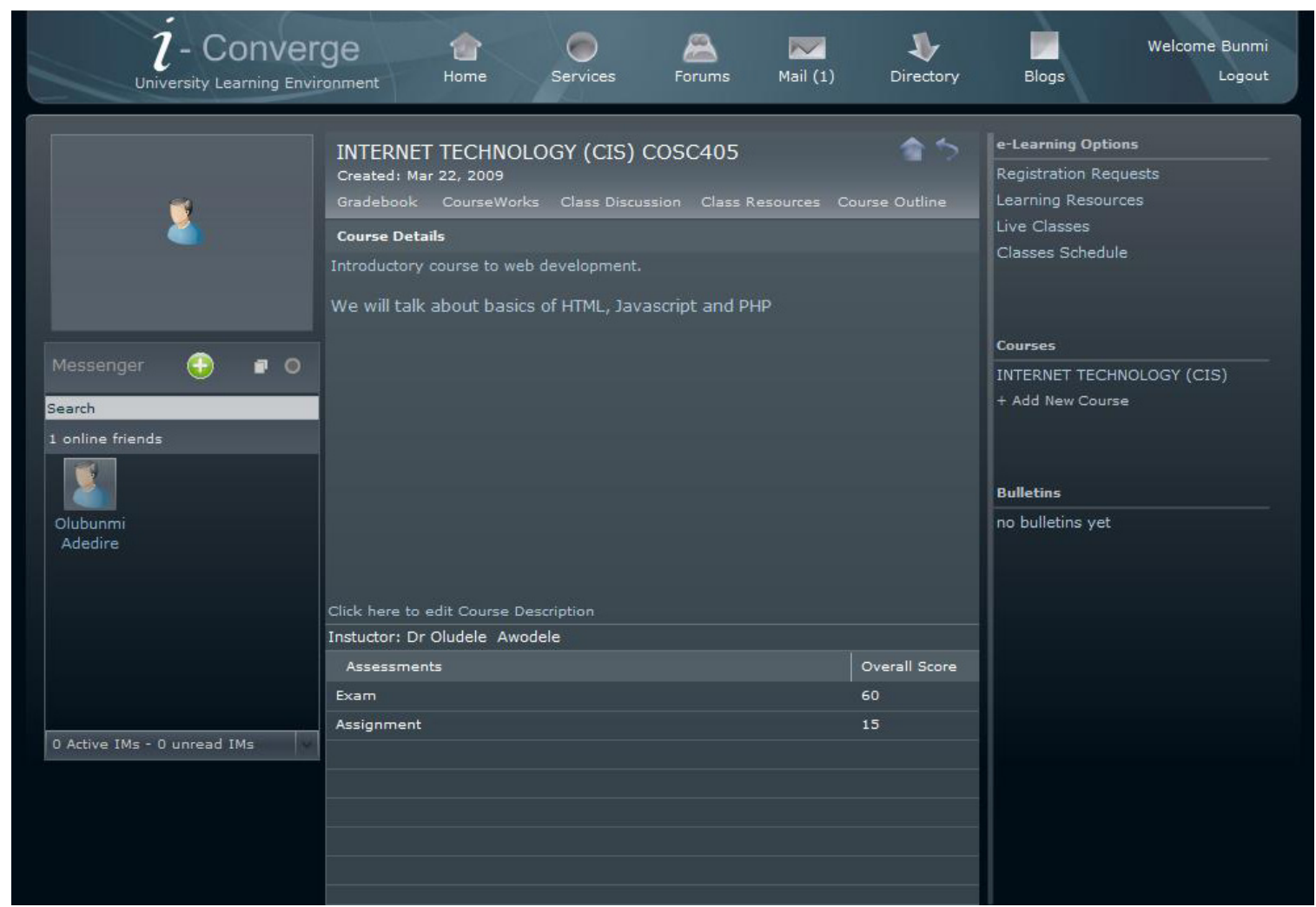

Figure 5: Course Management View

Figure 5 shows where lecturers manage created class. At the centre of the right bar of the elearning central is a list of courses created by the lecturer. Selecting a course opens the course management view. Here lectures can manage gradebook items (assessments), coursework's, course description, class discussion etc.

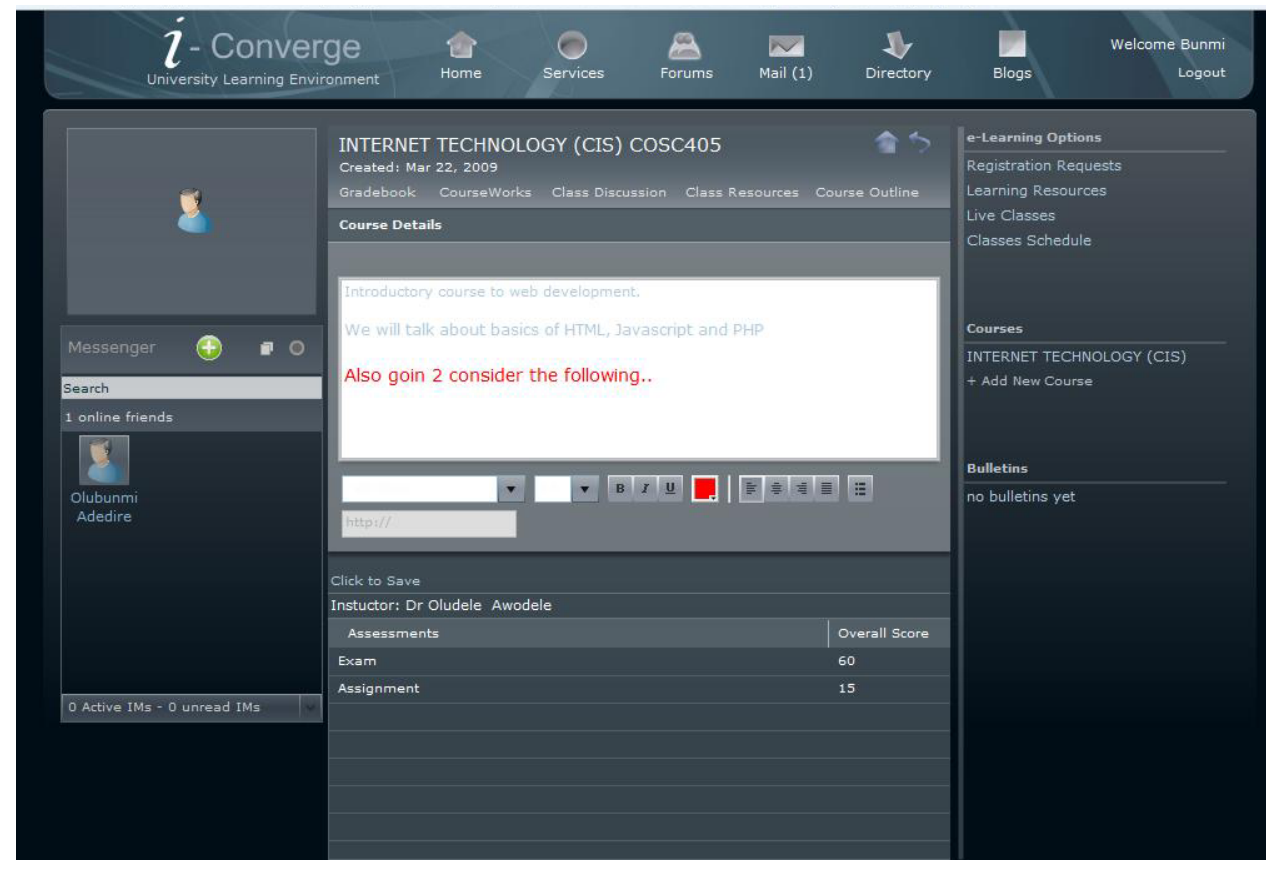

Figure 6: Editing Course Description 
Figure 6 shows how a lecturer can edit the course description. This is done by clicking on the edit link and click to save when done.

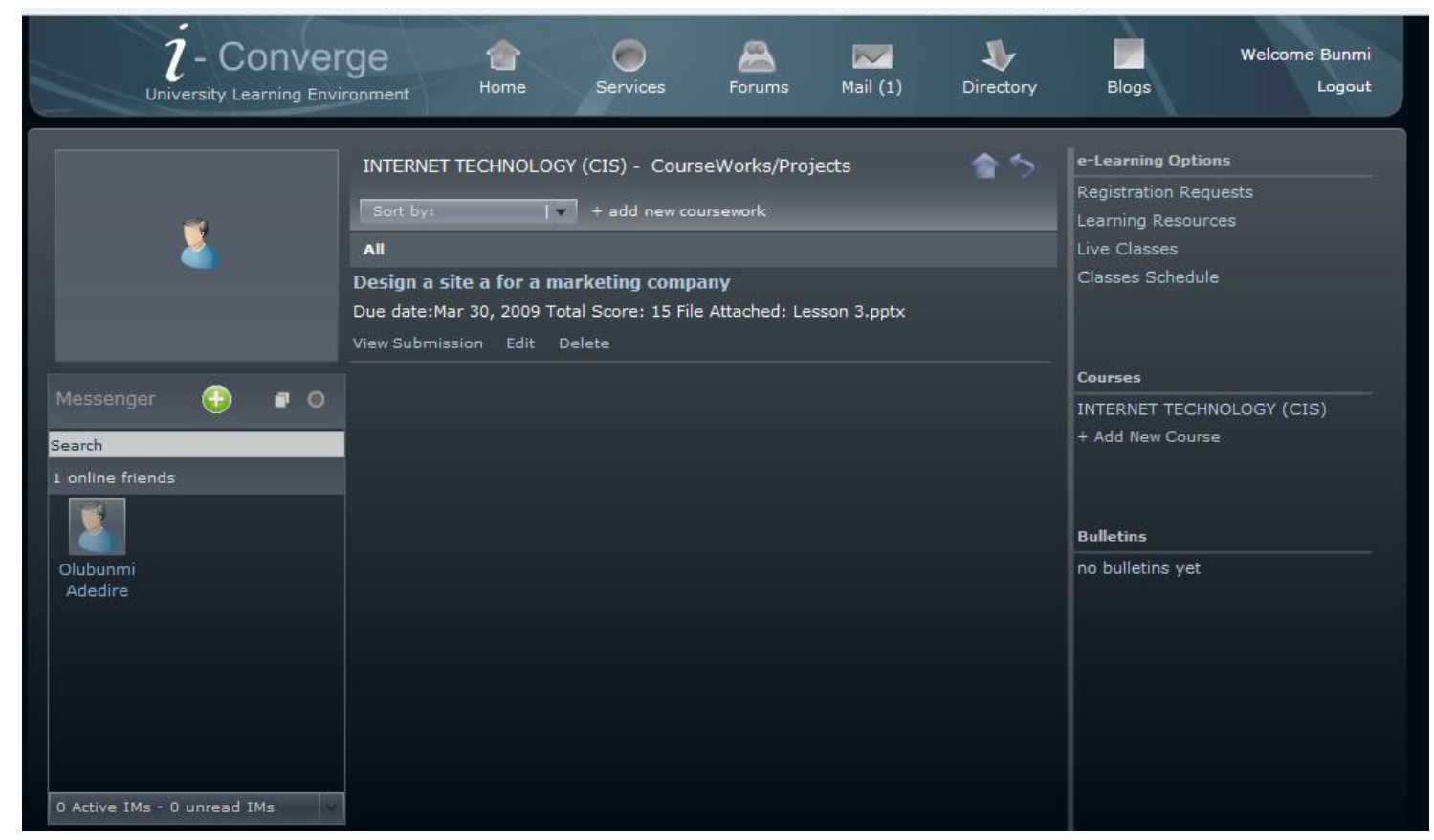

Figure 7: Managing Coursework

Figure 7 shows the view for creating new and managing existing course works. To create a new coursework the lecturer simply clicks on add new coursework. The view in Figure 8 shows the new coursework window, where the lecturer specifies the title, question, comment, score and deadline date. The Lecturer can also attach files to the coursework.

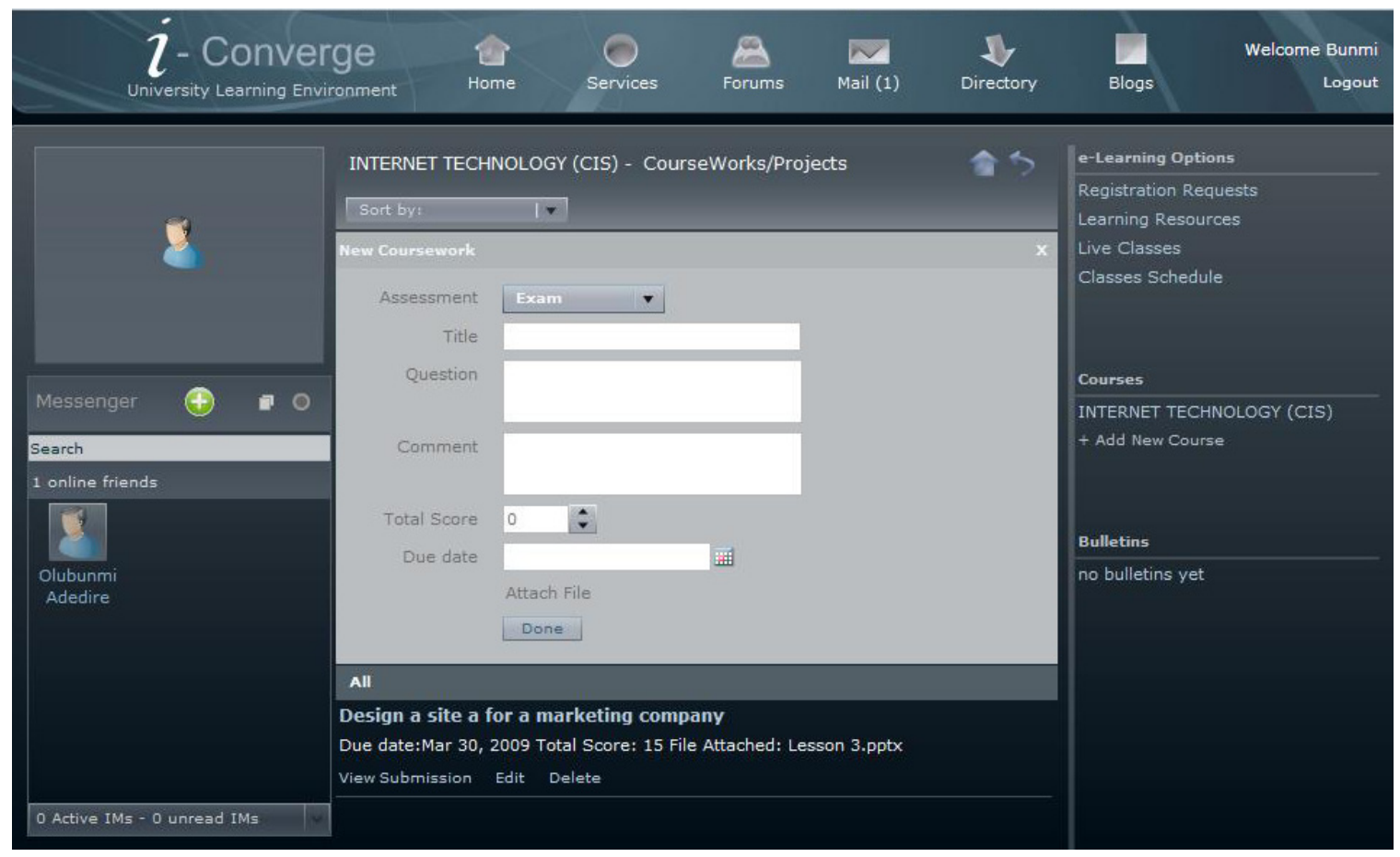

Figure 8: New Coursework View 


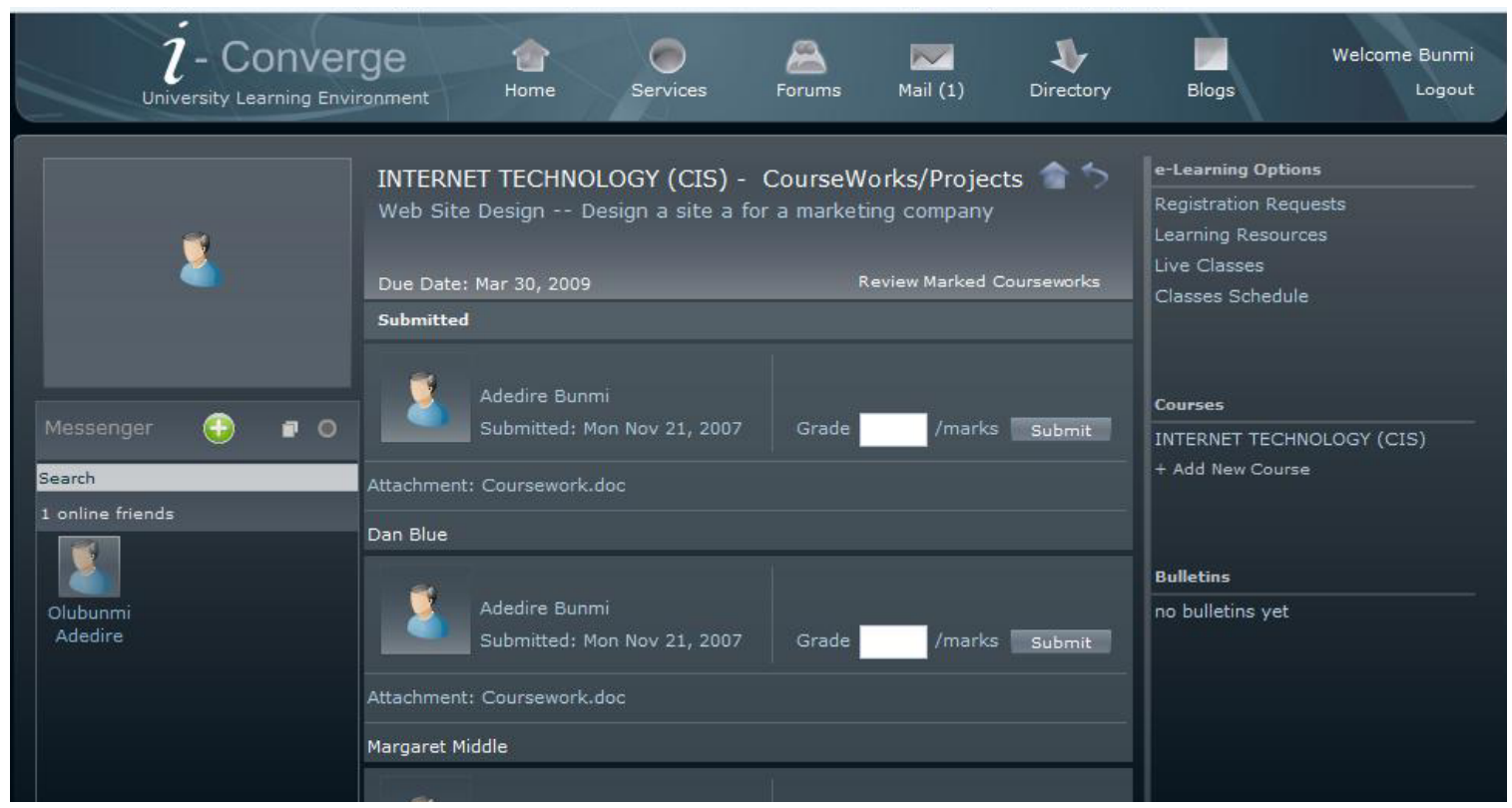

Figure 9: View Submission

Figure 9 shows the view where a lecturer views submissions for a coursework and assigns scores to them.

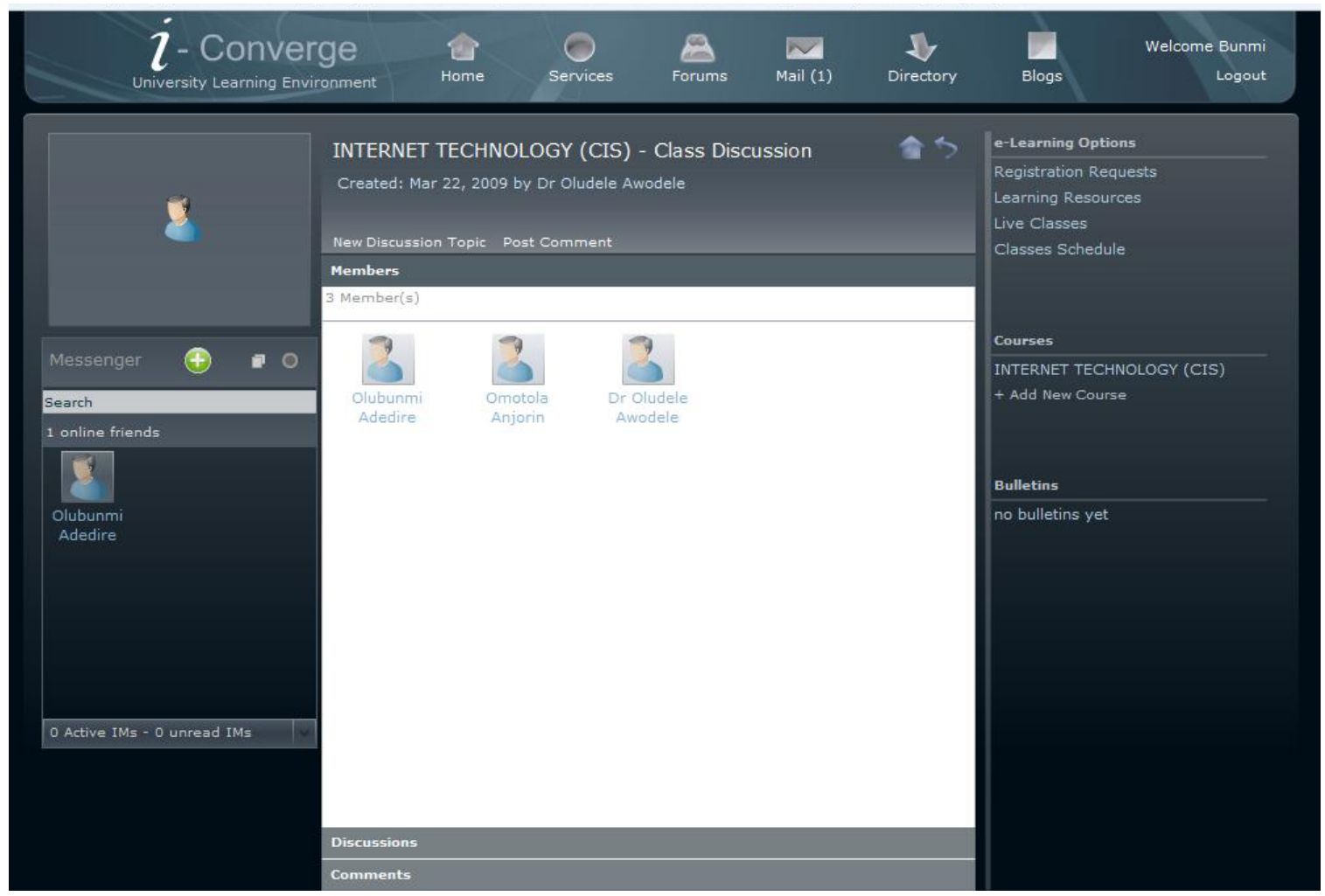

Figure 10: Class Discussion

Figure 10 shows the class discussion view. It is automatically created when a lecturer creates a new course and students automatically become members when they register for the class. The view has 3 tabs, the members, the topics and comments. 


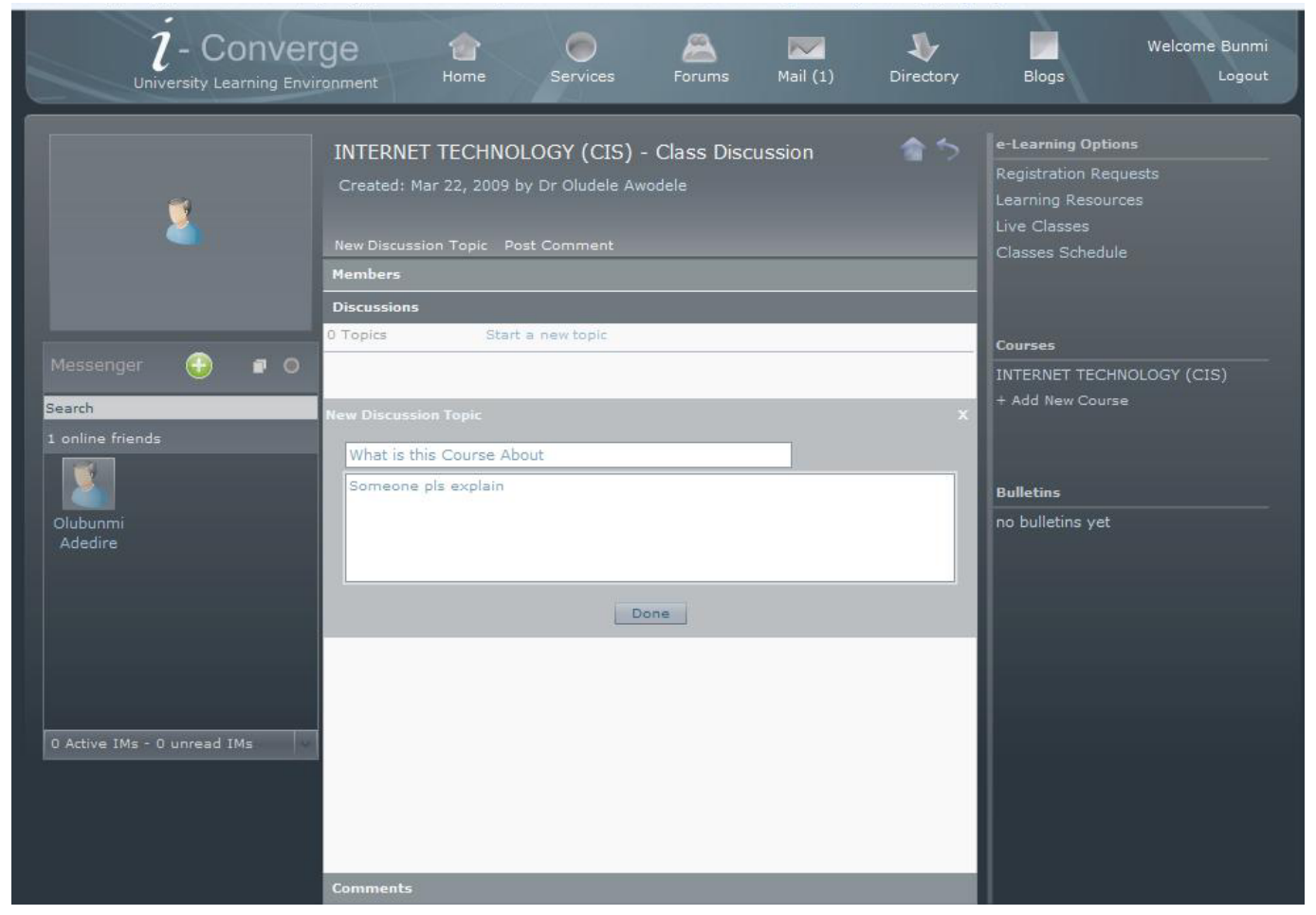

Figure 11: New Discussion Topic

Figure 11 shows how a new discussion topic is created.

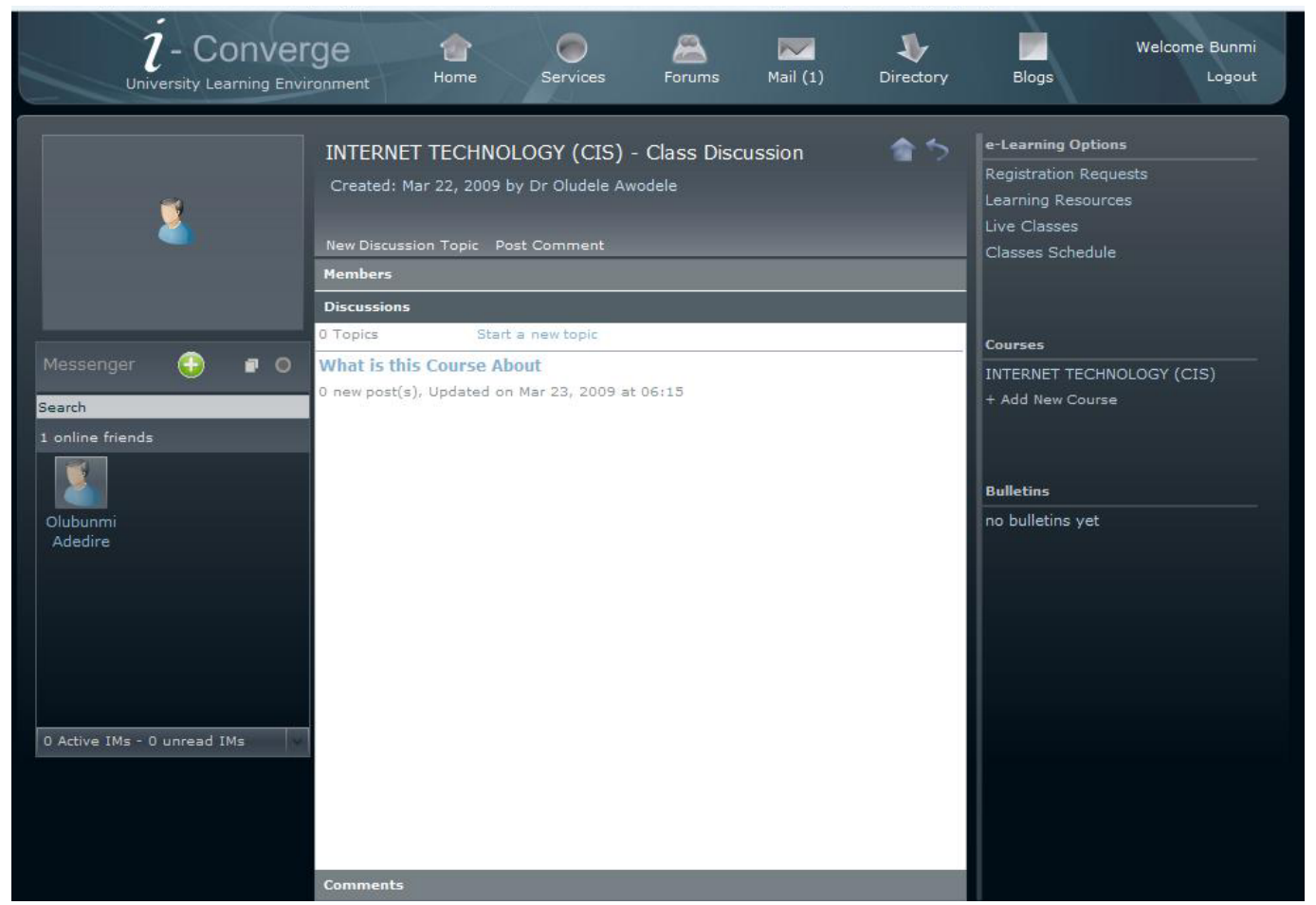

Figure 12: Discussion Topics

Figure 12 shows the view that lists the created topics, the number of posts they have, and when they were created or updated. 


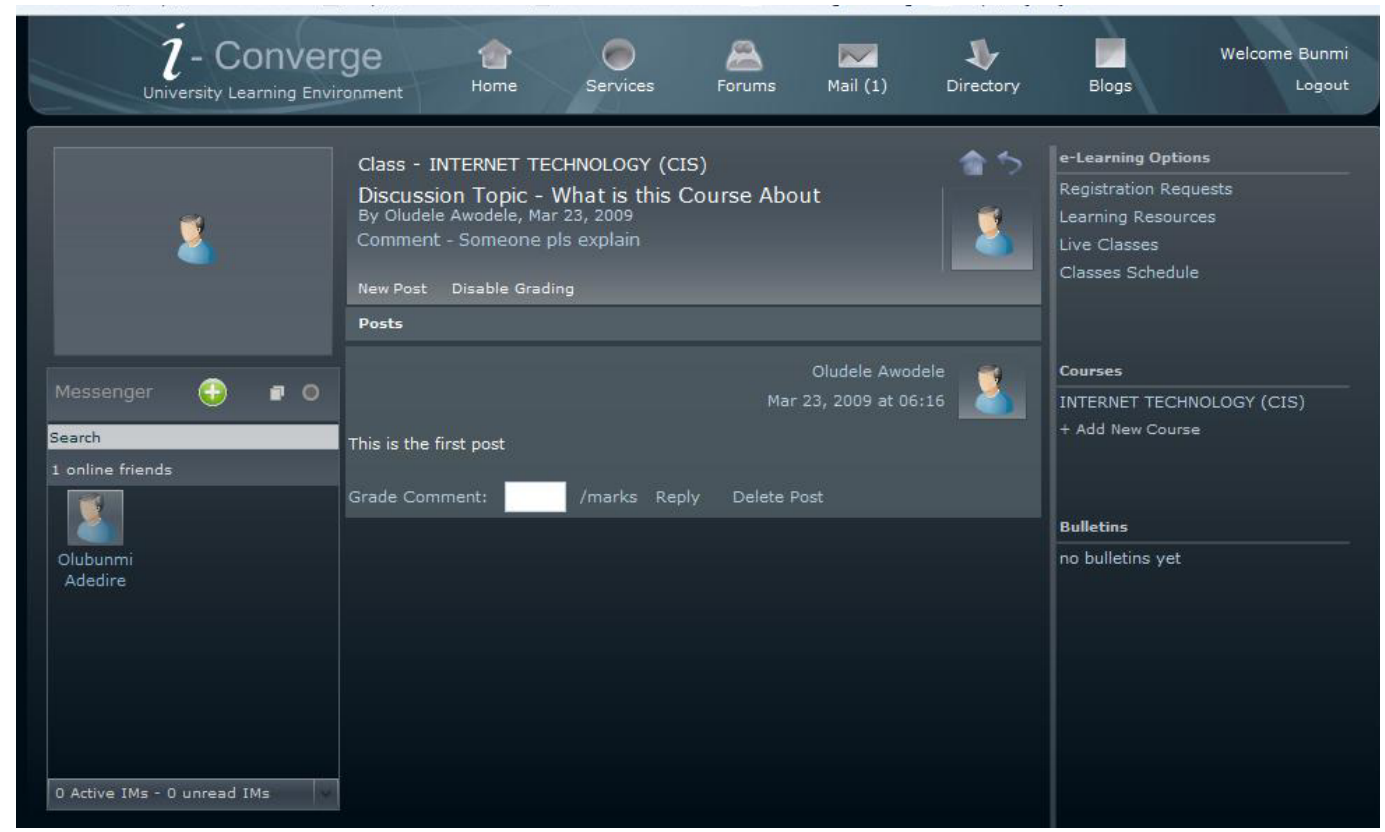

Figure 13: Discussion Topic View

Figure 13 shows the view of a discussion topic. Here the full details are shown and all the posts are also displayed. A new post can be added by click on the New Post button. It is also possible to grade comments in a class discussion and users can reply to previous comments.

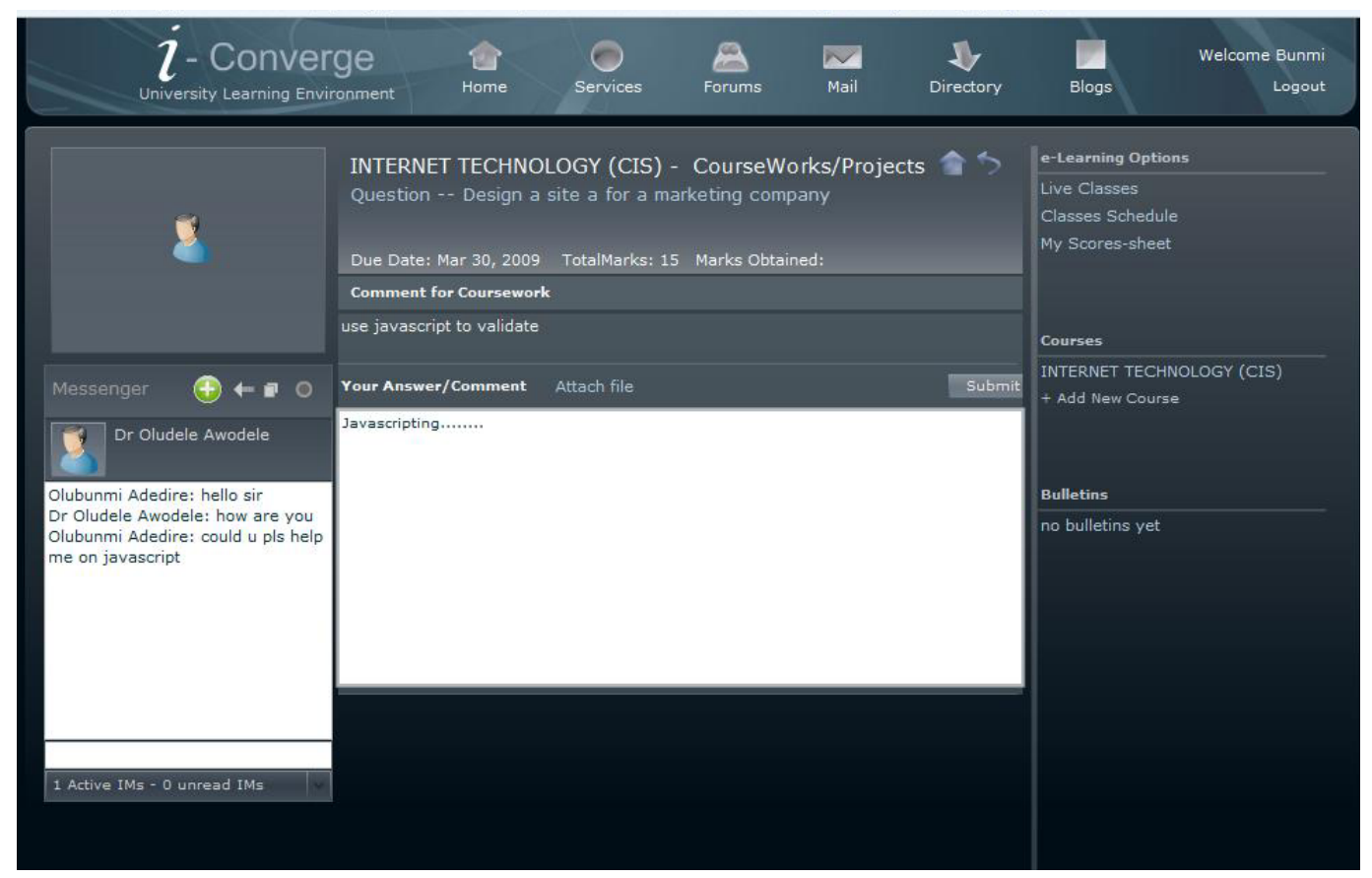

Figure 14: Student Submitting Coursework and Instant Messaging

Figure 14 provides the view of a student submitting a coursework and engaging in an instant messaging conversation simultaneously. The student can attach a file and/or enter answers directly. Submission is only allowed on or before the specified due date for the course work, and it is accepted once. 


\section{Live Class Management}

The live class part of the system is an interesting feature to us because it provides an opportunity for lecturers to deliver remote classes to large number of students regardless of where they are located. It makes distance learning possible. The live class section has a video/voice streaming view which also comes with an illustration tool (blackboard) and a real time chat room. Figure 15 shows the view for scheduling a live class. The lecturer can schedule a new live class by clicking on Schedule new, selecting any of his/her created courses and specifying the date and time for the class.

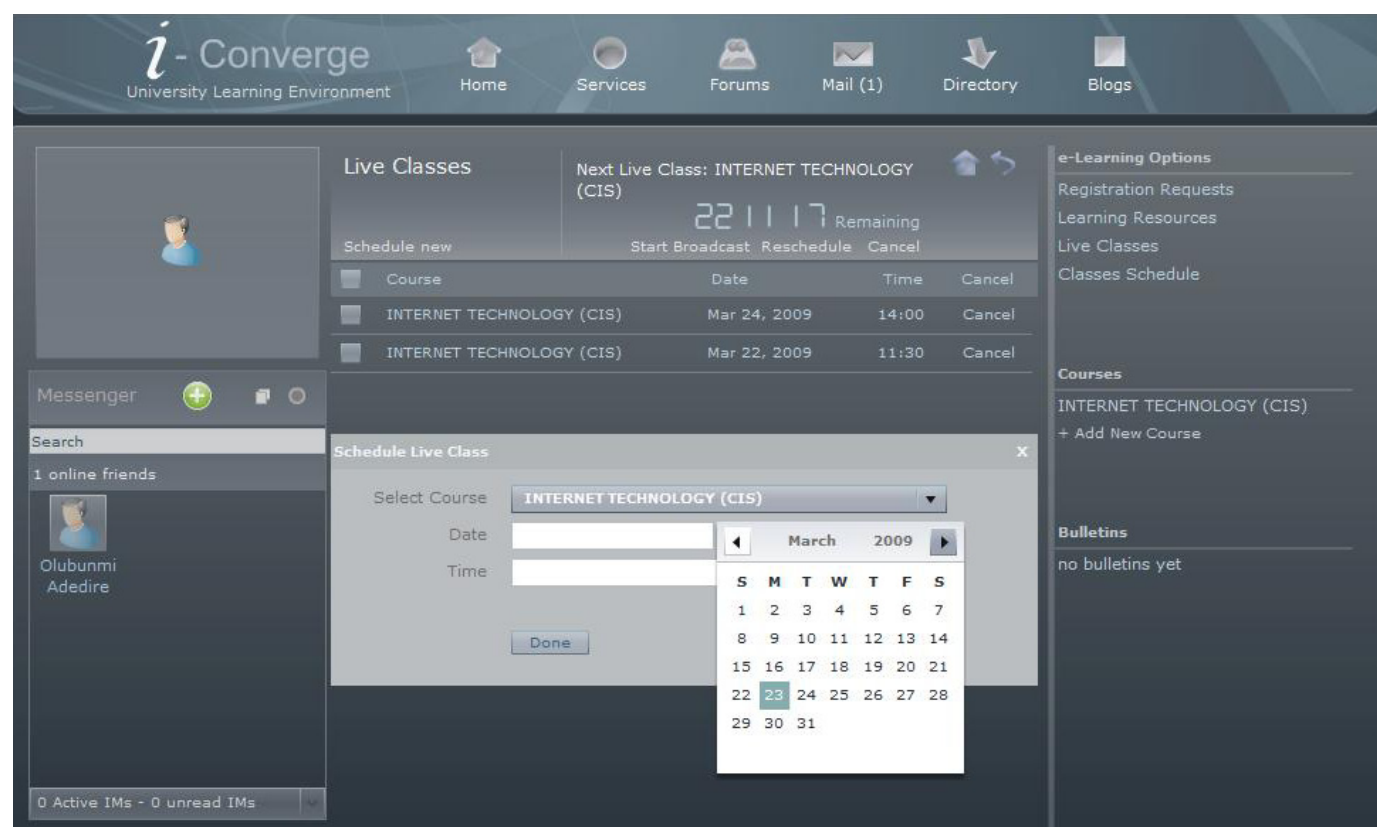

Figure 15: Scheduling Live Class

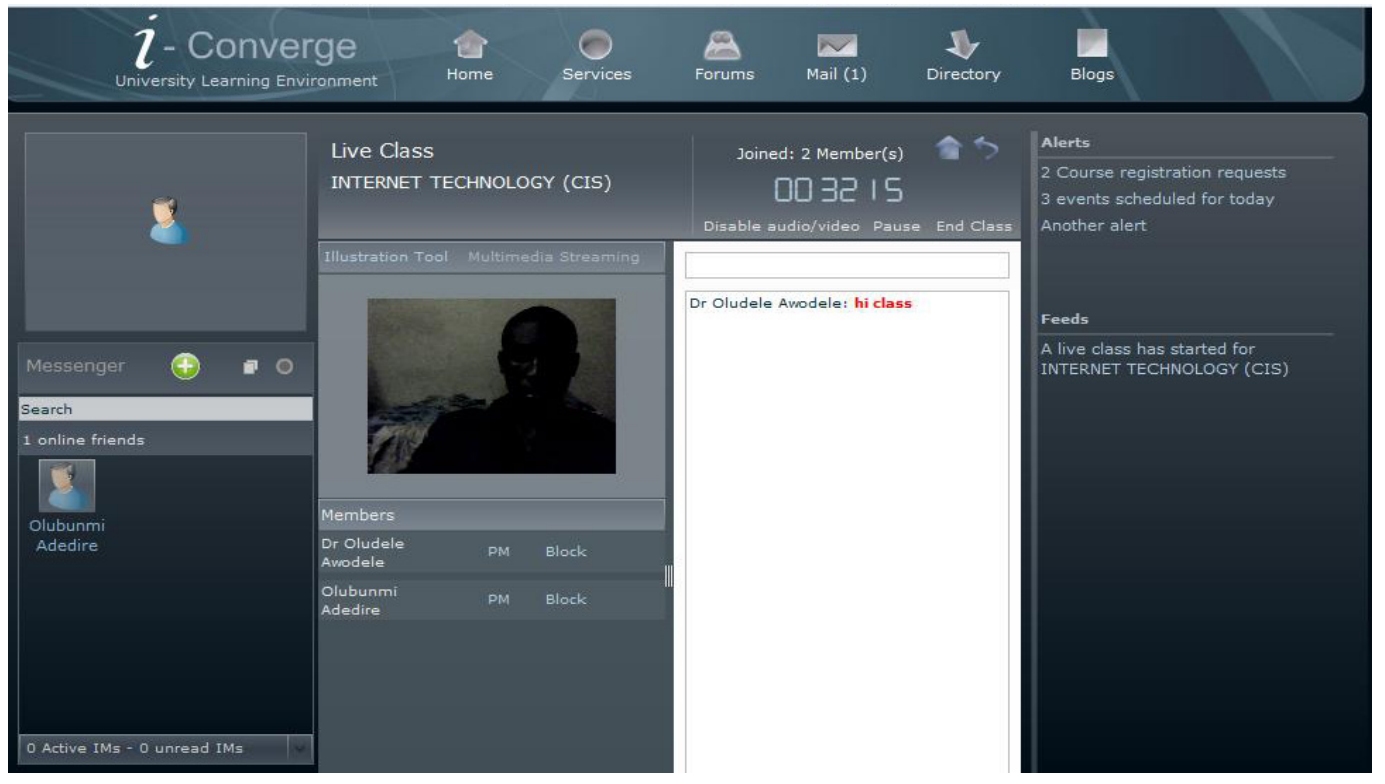

Figure 16: Broadcasting Live Class

Figure 16 shows a live class in broadcast, the broadcast show all members joined to the class and provides a chat tool for communication between the lecturer and the students. The students can 
see, hear and chat with the lecturer real-time. A black board tool is also provided for the lecturer to make notes and illustration. This can be used by clicking on the Illustration Tool option.

Figure 17 shows the use of the blackboard tool during a live class.

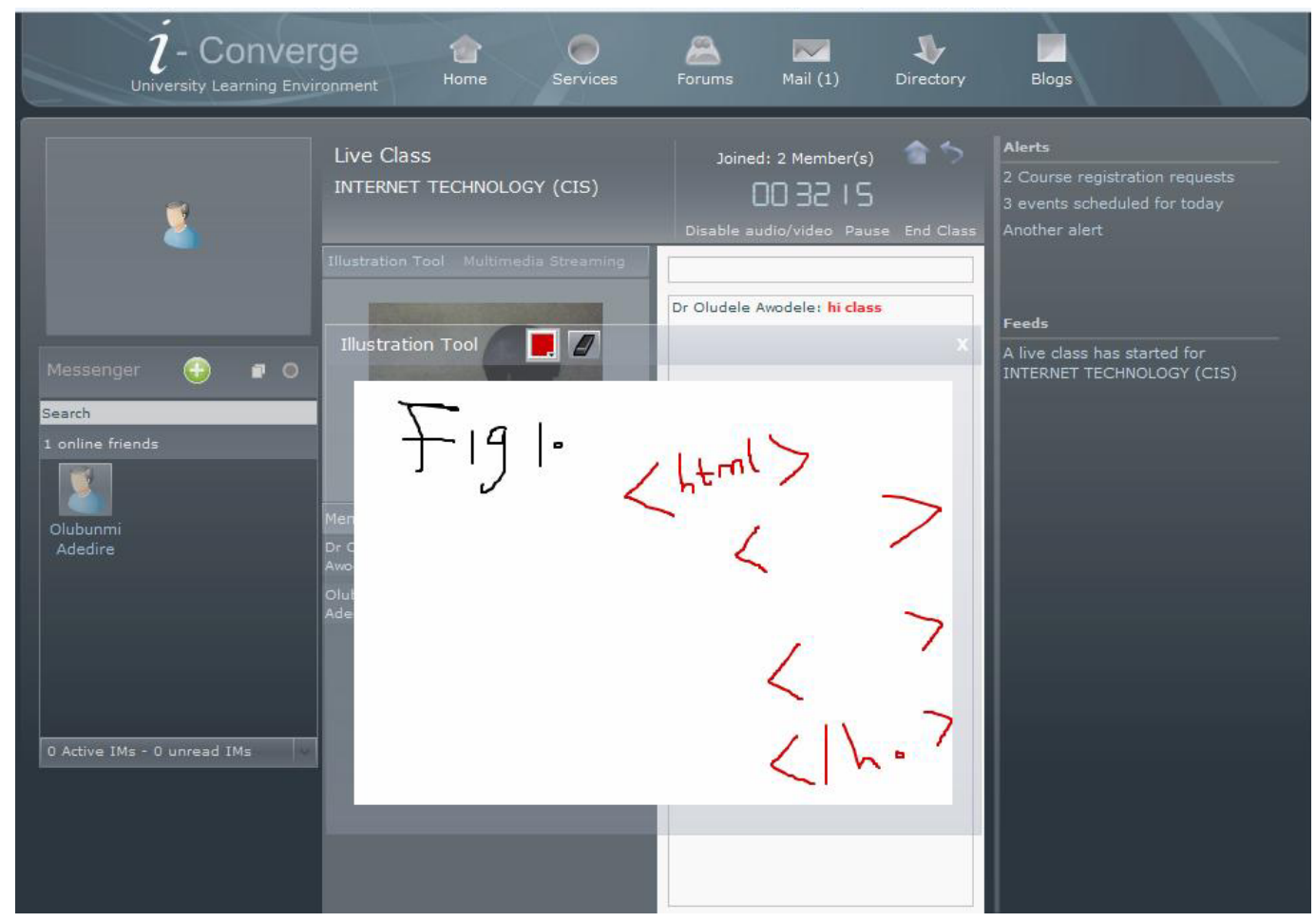

Figure 17: Live Steaming with Blackboard

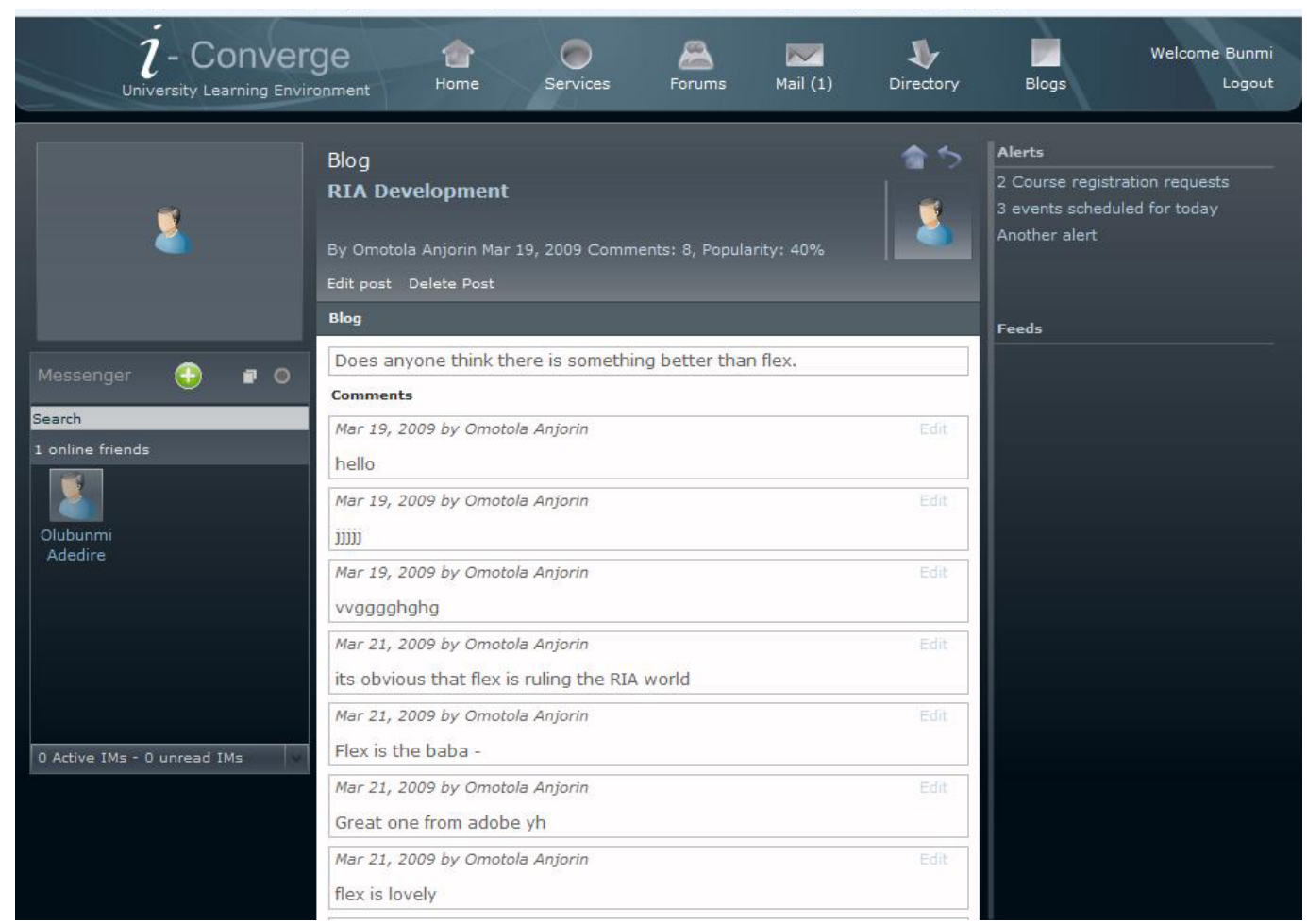

Figure 18: Blog Home 
Figure 18 shows a personal blog view. The title of the blog, author, popularity and number of comments are displayed at the top. All comments are listed and any user can post a new comment by typing his/her own opinion and clicking the submit button. The new blog comment view is shown in Figure 19.

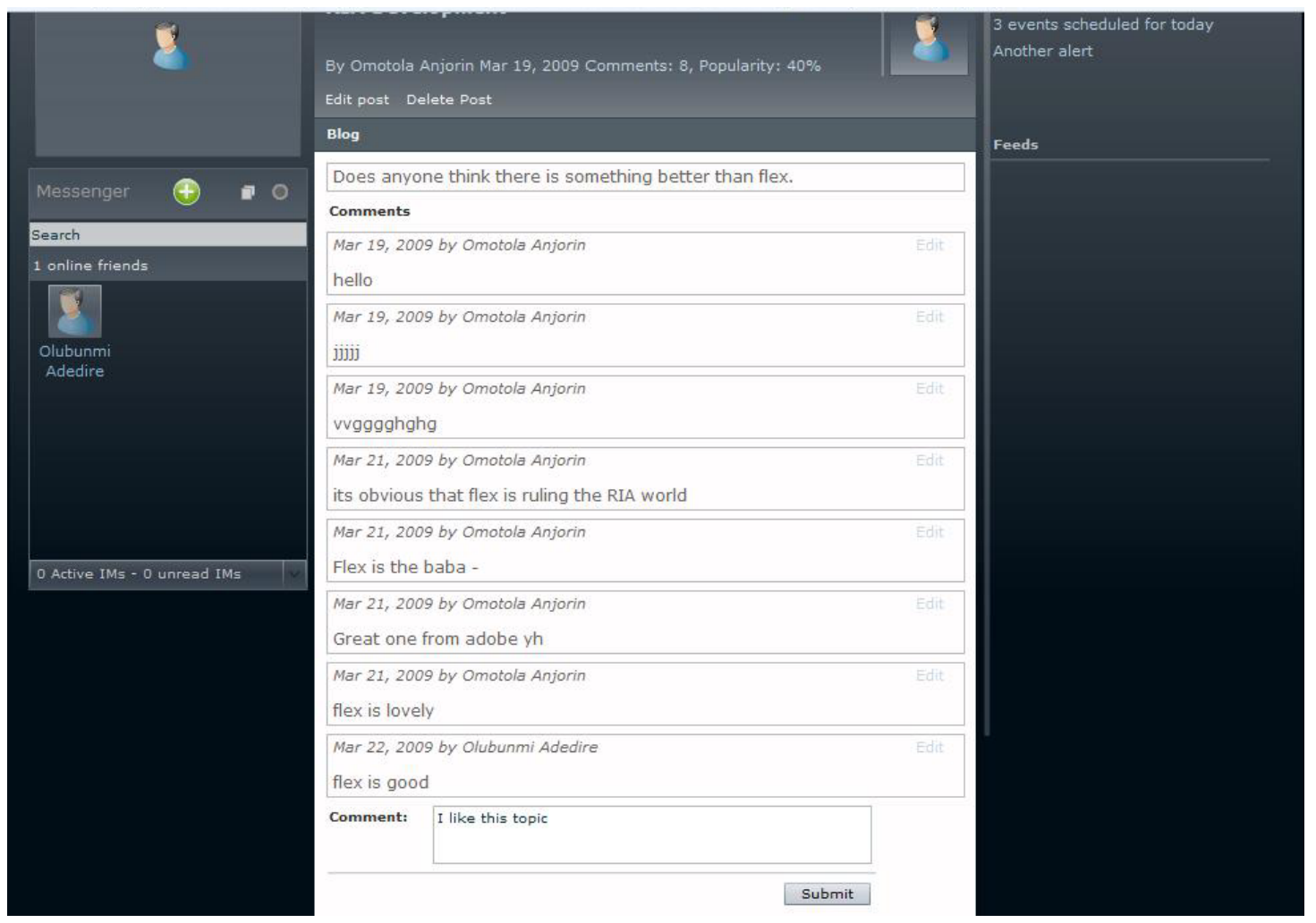

Figure 19: Posting a new comment

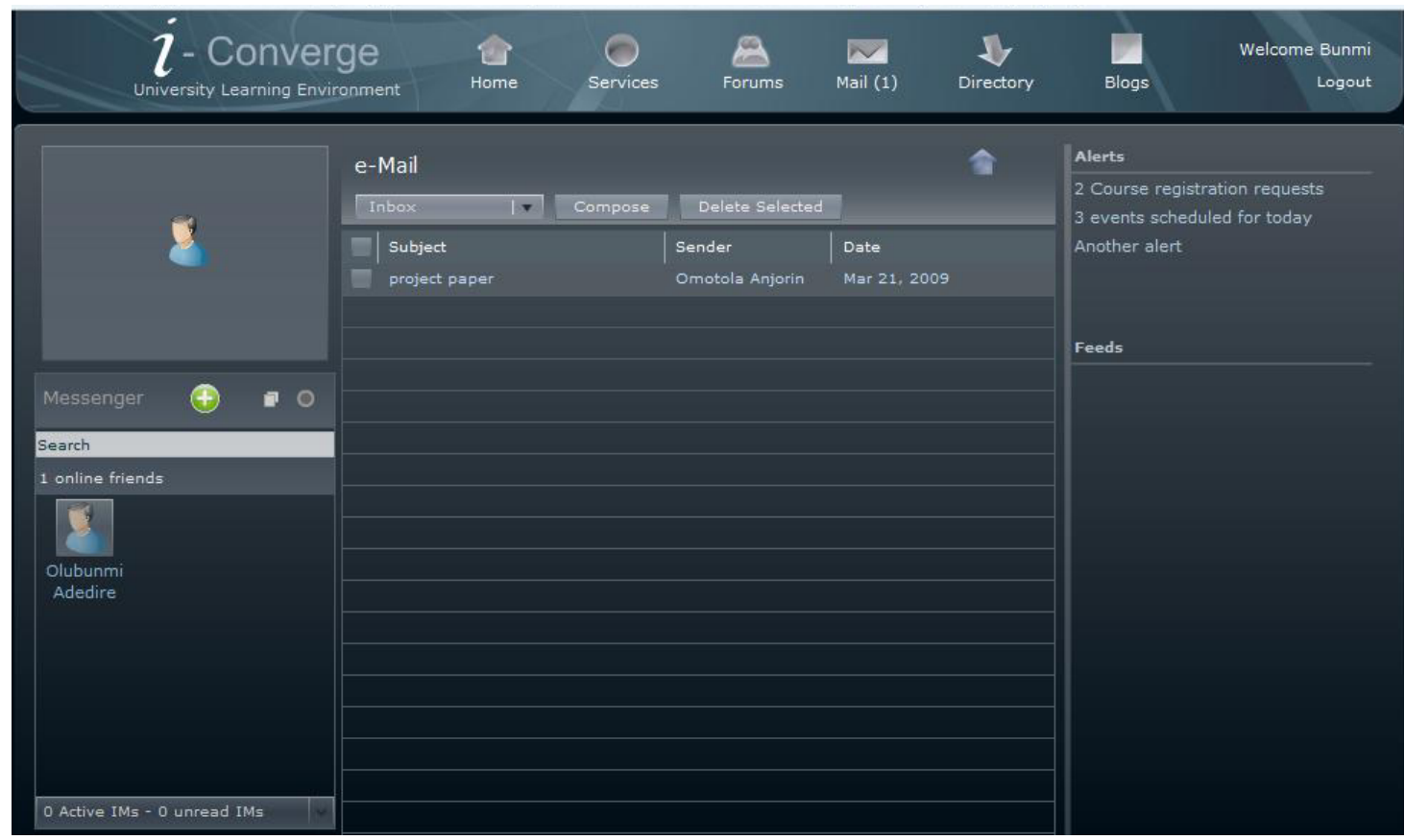

Figure 20: Email 
Figure 20 shows the email view; here users can view their inbox, sent messages and drafts. A user double clicks a mail to read it, and the user can reply the mail. A new mail is created by clicking on the compose button. A mail can be sent or saved as draft for future use.

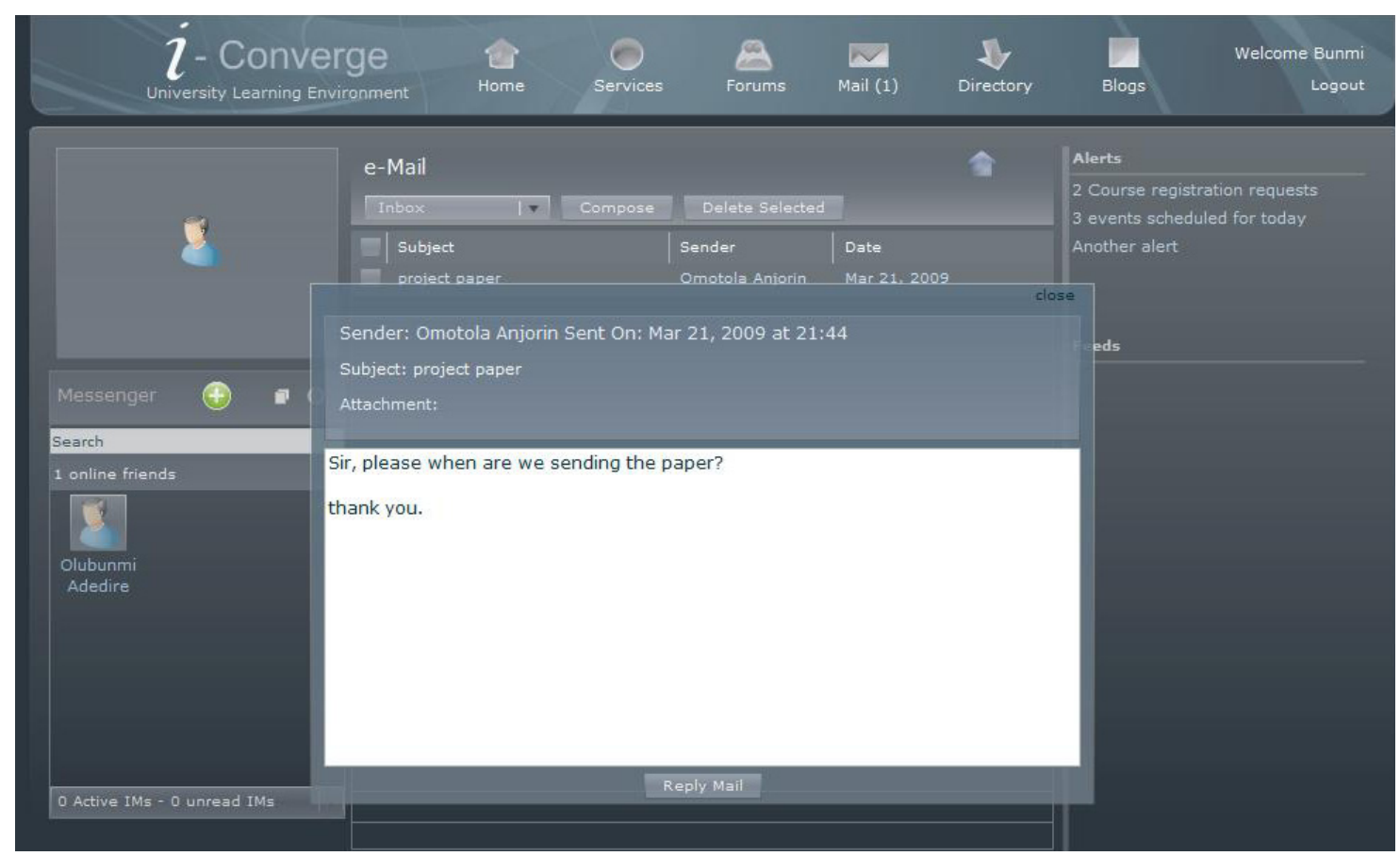

Figure 21: Read Mail

Figure 21 shows the read mail view. This view allows user to read mails and provides a link to reply the message. Users are updated real time when they receive a new message.

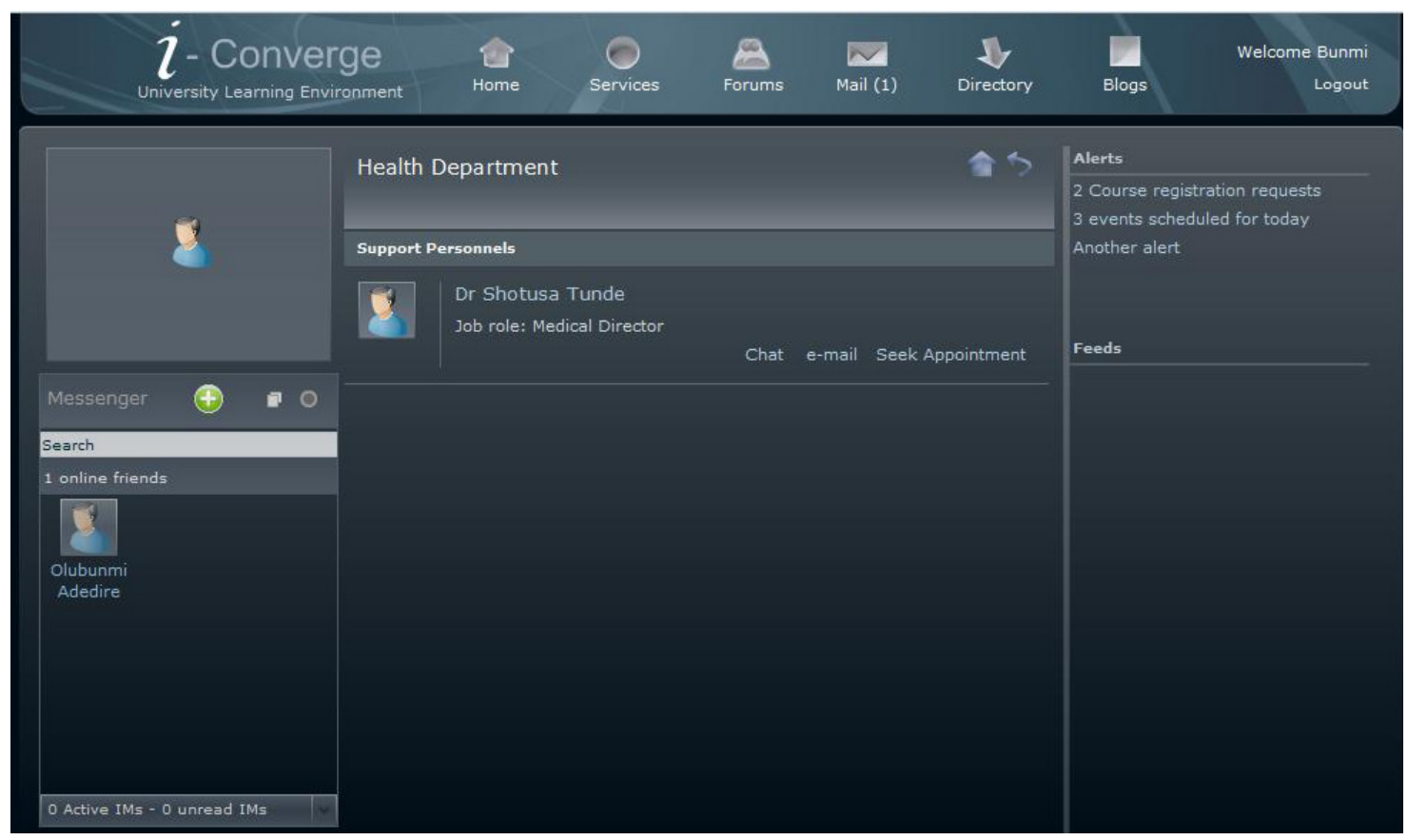

Figure 22: Using Health Services 
Awodele, Idowu, Vincent, Anjorin, Adedire, \& Akpore

Figure 22 shows a user using the health services on the system. To access this service, the user selects the Health Department from the Services menu (top). The view then shows all health personnel online and lets the user seek an appointment, chat or email the person. The health department interfaces another hospital information system used at the medical centre of the university.

\section{Further Work}

$i$-Converge is still a work in progress, and we are committed to extending the services and features provided by the system. We are considering new mechanism of securing the system and implementing adequate concurrency control mechanism. We are also researching into how other administrative units within private universities can be integrated into the system, such that the system provides a real virtual university with access to primarily all activities and services available on the university campus.

\section{Conclusion}

Private universities are making a great impact in the educational sector of Nigeria. The quality of graduates they turn out backed up with the infrastructural development existing in these schools suggest that it is only a matter of time before they take over the academic light of the country.

It is obvious that what determines how good a university is among many factors is the infrastructural facility, conducive environment for learning and research and development, and the calibre of personnel's. Therefore, adopting an e-learning system can help give that required leverage to private universities. Also, a system like $i$-Converge poses an opportunity for private universities to make money outside the campus by considering distant learning program.

\section{References}

Aviram, A., Ronen, Y., Somekh, S., Winer, A., \& Sarid, A. (2008). Self regulated personalized learning (SRPL): Developing iClass's pedagogical model. eLearning Papers No 9. ISSN: 1887-1542

Anderson, P. (2007). What is Web 2.0? Ideas, technologies and implications for education. JISC reports. Retrieved October 4, 2008, from http://www.jisc.ac.uk/media/documents/techwatch/tsw0701b.pdf

Awodele, O., Idowu, S., Anjorin, O., Adedire, O., \& Apkore, V. (2009). University Enhancement System Using a Social Networking Approach: Extending E-learning. Issues in Informing Science and Information Technology (IISIT), Volume 6, pages 269-283.

Brown, J. S., \& Adler, R.P. (2008). Minds on fire: Open education, the long tail, and learning 2.0. Education Review, 43(1), 16-32. Retrieved December 6, 2008 from http://www.educause.edu/ir/library/pdf/ERM0811.pdf

Chua, B. B., \& Dyson, L. E. (2004). Applying the ISO9126 model to the evaluation of an e-learning system. In R. Atkinson, C. McBeath, D. Jonas-Dwyer, \& R. Phillips (Eds.), Beyond the comfort zone: Proceedings of the 21st ASCILITE Conference (pp.184-190). Perth, 5-8 December.

O'Reilly, T. (2005). What is Web 2.0. Design pattern and business models for the next generations of software. Retrieved December 1, 2008 from http://www.oreillynet.com/pub/a/oreilly/tim/news/2005/09/30/what-is-web-20.html

Obasi. I. N. (2007). Analysis of the emergence and development of private universities in Nigeria (19992006). JHEA/RESA, 5(2\&3), 39-66. 


\section{Biographies}

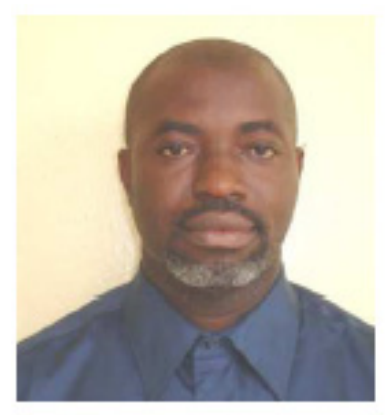

Oludele Awodele Ph.D is presently a senior lecturer in the department of computer science \& mathematics, Babcock University, IlishanRemo, Ogun State, Nigeria. His research areas are Software Engineering, Data Communication and Artificial Intelligence. He has published works in several journals of international repute. He can be contacted atdelealways@yahoo.com.

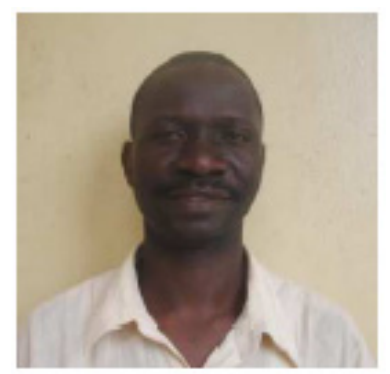

Sunday Idowu is associate Professor in the department of computer science \& mathematics, Babcock University, Ilishan-Remo, Ogun State, Nigeria. He holds a Masters degree in Software Engineering, and he is currently working on his Ph.D in the University of Ibadan, Oyo State, Nigeria. His research areas are Software Engineering, Web Application Development and Security. He has published works in several journals of international repute. He can be contacted at saidowu06@hotmail.com.

Vincent Jonah Joshua is a lecturer in the department of computer science \& mathematics, Babcock University, Ilishan-Remo, Ogun State, Nigeria. He is a software engineer with many years of technical experience. His areas of reseach work include database management and object oriented programming. He can be contacted atjvjoshua@hotmail.com

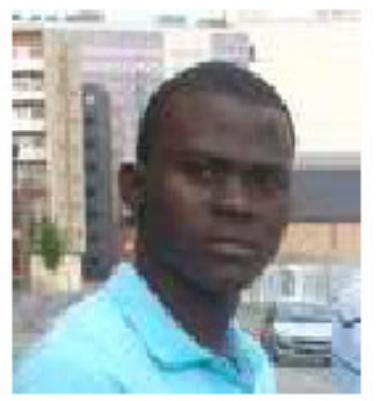

Omotola Anjorin graduated June 2009 from Babcock University,Ilishan-Remo, Ogun State, Nigeria. He is a member of the Nigerian Computer Society, and the International Institute of Electrical and Electronic Engineers (IEEE). His areas of interest include Database Technologies, Software Development, Systems Administration and Networking. He is a Microsoft Certified Professional, a Microsoft Certified Systems Administrator and a Cisco Certified Network Associate. He can be contacted at anjorin_jnr@hotmail.com.

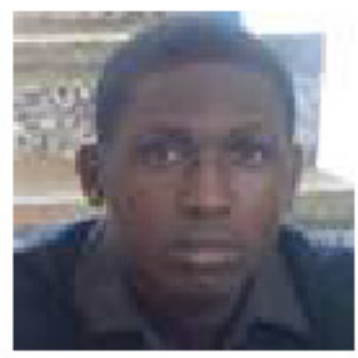

Olubunmi Adedire graduated June 2009 from Babcock University, Ilishan-Remo, Ogun State, Nigeria. His area of interest includes interface design, software development and animation. He is conversant with the use of several Adobe technologies in developing E-learning solutions. He can be contacted at bunmie me@yahoo.com. 


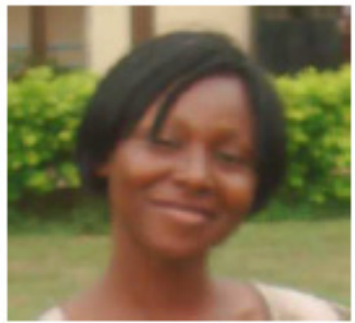

Victoria Akpore graduated June 2009 from Babcock University, Ilishan-Remo, Ogun State, Nigeria. Her areas of interest include Networking, Databases and Accounting. She holds the Cisco Certified Network Associate and Oracle Certified Associate certifications. Her e-mail is vicakpore@yahoo.co.uk 